\title{
Correction to: Inactivation of the Ras/MAPK/PPAR $y$ signaling axis alleviates diabetic mellitus-induced erectile dysfunction through suppression of corpus cavernosal endothelial cell apoptosis by inhibiting HMGCS2 expression
}

\section{Zhuo Zhang $^{1} \cdot$ Hai-Yan Zhang ${ }^{2} \cdot$ Ying Zhang $^{3} \cdot \mathrm{Hai} \mathrm{Li}^{1}$}

Published online: 4 January 2021

(c) Springer Science+Business Media, LLC, part of Springer Nature 2020

Correction to: Endocrine

https://doi.org/10.1007/s12020-018-1810-2
The original version of the article unfortunately contained an error in the image of Fig. 5. The corrected Fig. 5 is given below:
These authors contributed equally: Zhuo Zhang, Hai-Yan Zhang

The original article can be found online at https://doi.org/10.1007/ s12020-018-1810-2.

Hai Li

lihai@jlu.edu.cn

1 Department of Urology, China-Japan Union Hospital of Jilin University, Changchun 130000, P.R. China

2 Department of Gastrointestinal Surgery, China-Japan Union Hospital of Jilin University, Changchun 130000, P.R. China

3 Department of Pathology, China-Japan Union Hospital of Jilin University, Changchun 130000, P.R. China 
A

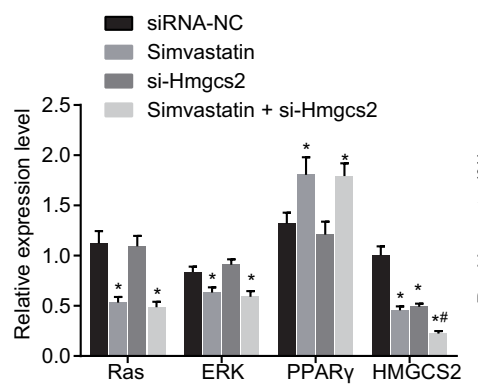

C

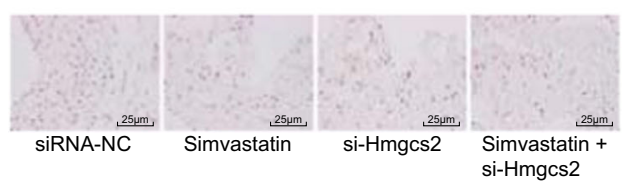

Fig. 5

B
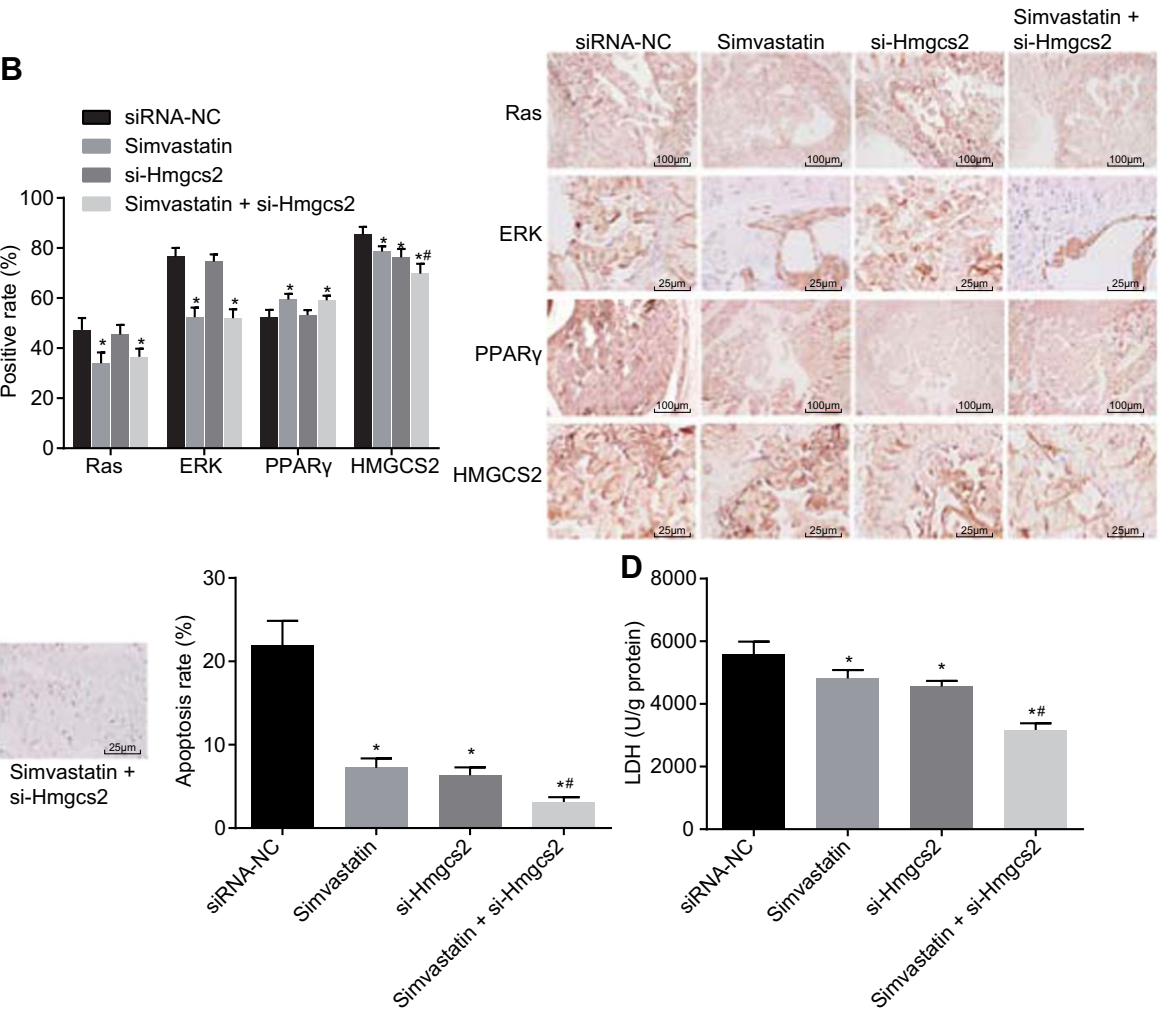